\title{
REPRESENTAÇÕES DE GRADUANDAS DE EDUCAÇÃO FÍSICA SOBRE CORPO, MULHER E MÍDIA
}

\author{
REPRESENTATIONS OF PHYSICAL EDUCATION GRADUATES \\ ON BODY, WOMAN AND MEDIA
}

\section{REPRESENTACIONES DE EDUCACIÓN FÍSICA DE CUERPO, MUJER Y MEDIOS DE COMUNICACIÓN}

\author{
Dieli MarTins QueIroZ ${ }^{1}$ \\ VAGNer Matias do Prado ${ }^{2}$ \\ Bacharel e Licenciada em Educação Física ${ }^{1}$ \\ Universidade Federal de Uberlândia ${ }^{2}$
}

\begin{abstract}
RESUmo O trabalho problematiza percepções de estudantes sobre a relação entre corpo, mulher e mídia. A perspectiva culturalista e os estudos de gênero foram adotados como aporte teórico para a investigação. O objetivo foi compreender, a partir de suas narrativas, como as representações midiáticas afetam o olhar das estudantes a respeito de seus corpos, bem como qual o impacto que atribuem às influências da mídia na produção do corpo da mulher. A pesquisa qualitativa, do tipo estudo de caso, utilizou-se de grupo focal com seis graduandas, as quais se autorrepresentavam como mulheres e cursavam o último período do curso de formação inicial em Educação Física, em uma instituição de ensino superior pública do interior do estado de Minas Gerais. Identificou-se que, para as colaboradoras, "ser" mulher se conecta com representações sociais e que as influências da mídia sob seus corpos se estabelecem na construção de padrões corporais esperados socialmente para as mulheres. De acordo com as estudantes, tal fato produz sentimentos negativos com relação ao próprio corpo, estabelece classificações e hierarquizações entre as mulheres e impacta nas possibilidades de reconhecimento profissional, no que se refere à futura inserção no mercado de trabalho, especialmente quando da atuação como profissional liberal, em acadêmicas de ginástica e musculação.
\end{abstract}

Palavras-chave: Mídia; Gênero; Construção do corpo da mulher.

AbSTRaCr This paper discusses student representations concerning the relationship between body, woman and media. The cultural perspective and gender studies were adopted as theoretical support for research. The objective herein was to understand, from their narra- 
tives, how media representations affect the view students have of their body, as well as the impact they attribute to media influences on the body production of women. The qualitative research, of the case study type, used a focus group with six undergraduates, who the self represents as women that attended the last period of the initial course of Physical Education in a public higher education institution in the interior of the state of Minas Gerais. It was identified that, for the collaborators, "being" a woman connects with social representations and that the influences of the media on their bodies are established in the construction of socially expected body patterns for women. According to the students, such a fact produces negative sentiments in relation to one's own body, establishes classifications and hierarchies among women, as well as impacting on the possibilities of professional recognition, when dealing with future insertion into the job market, especially when working freelance, in athletics and workout gyms.

Keywords: Media Education; Gender Difference; Woman; Body.

RESUMEN El artículo cuestiona las percepciones de los estudiantes sobre la relación entre el cuerpo, la mujer y los medios. La perspectiva culturalista y los estudios de género fueron adoptados como soporte teórico para la investigación. El objetivo era comprender, a partir de sus narraciones, cómo las representaciones de los medios afectan la visión de los estudiantes sobre sus cuerpos, así como el impacto que atribuyen a las influencias de los medios en la producción corporal de las mujeres. La investigación del estudio de caso cualitativo utilizó un grupo focal con seis estudiantes universitarios, quienes se representaron a sí mismos como mujeres y asistieron al último período del curso inicial de Educación Física en una institución pública de educación superior en el interior del estado. estado de Minas Gerais. Se descubrió que, para los colaboradores, "ser" una mujer se conecta con las representaciones sociales y que las influencias de los medios en sus cuerpos se establecen en la construcción de patrones corporales socialmente esperados para las mujeres. Según los estudiantes, este hecho produce sentimientos negativos sobre sus propios cuerpos, establece clasificaciones y jerarquías entre las mujeres e impacta en las posibilidades de reconocimiento profesional, con respecto a la inserción futura en el mercado laboral, especialmente cuando se actúa como profesional. liberal, en gimnasia y culturismo.

Palabras Claves: Medios de comunicación; Género; Construcción del Cuerpo de LA MUJER.

\section{INTRODUÇÃo}

As relações de gênero vêm sendo discutidas em diversos espaços, e cabe também à Educação Física, como área de produção de conhecimentos e intervenção social, problematizar os corpos como produtos socioculturais os quais são interpelados por essas relações. Em uma rápida incursão em bases de dados, percebemos a timidez da área em provocar questionamentos sobre o corpo, a partir do viés culturalista, e como esse aparente "dado natural" é, constantemente, (re)produzido por diferentes práticas discursivas.

A problematização sobre os processos de padronização e controle social do corpo da mulher foi o ponto de partida para a discussão desse tema. Como problemas de investiga- 
ção, elencamos: de que maneira as representações midiáticas afetam o olhar de estudantes de Educação Física sobre seus corpos? Qual o impacto que atribuem às influências da mídia na produção do corpo da mulher?

Estruturalmente, após esta introdução, apresentamos o delineamento metodológico do estudo. Segue-se a isso uma revisão da literatura sobre os temas centrais da investigação. Em sequência, são expostos os resultados e a discussão a que fomos direcionados. Por fim, apresentamos nossas considerações e as vozes teóricas que nos auxiliaram, durante o processo de conclusão da pesquisa.

\section{Procedimentos metodológicos}

A pesquisa caracteriza-se como de abordagem qualitativa (ANDRÉ; LÜDKE, 2013; MINAYO, 2006). Para André e Lüdke (2013) tal abordagem permite partir de um universo amplo (tema) e, a partir do desenvolvimento do estudo, delimitar questões mais específicas para responder aos problemas de pesquisa elencados. A opção pelo delineamento foi o estudo de caso, representado por um "[...] estudo profundo e exaustivo de um ou de poucos objetos, de maneira a permitir o seu conhecimento amplo e detalhado." (GIL, 2010, p. 58). Cabe ainda destacar que o estudo de caso remete tanto a um caso simples como de questões complexas e abstratas (ANDRÉ; LÜDKE, 2013).

Como instrumento para a geração de dados, foi utilizado o Grupo Focal (GF), o qual se caracteriza como um grupo de discussão informal e de tamanho reduzido, que tem como finalidade auxiliar o pesquisador a obter informações de caráter qualitativo em profundidade (MORGAN, 1997). O objetivo principal de um GF é revelar as percepções dos participantes acerca dos tópicos em discussão.

A população foi constituída por seis mulheres, graduandas do curso de Educação Física de uma universidade pública localizada no interior do estado de Minas Gerais. Todas as estudantes estavam matriculadas no último período de formação inicial e foram convidadas a participar, sendo que os critérios de inclusão adotados foram: 1) estudantes, as quais se autorrepresentavam como mulheres, tendo em vista sua identidade de gênero; 2) que se encontravam matriculadas no último período do curso de graduação; 3) que fossem estudantes do período regular da turma de ingresso; 4) que aceitassem participar, de forma espontânea, da investigação.

Antes de suas participações cada colaboradora recebeu, leu e assinou um Termo de Consentimento Livre e Esclarecido (TCLE). Tais cuidados remetem ao atendimento da Resolução 466/2012 do Conselho Nacional de Saúde sobre os princípios éticos de pesquisa com seres humanos.

Foi conduzida uma sessão de GF com o grupo participante, em função da estruturação de um roteiro. Para iniciar a discussão, foi exibido um vídeo sobre uma propaganda publicitária de uma marca de cerveja. ${ }^{1}$ A reunião teve duração de 28 minutos e, ao final da sessão, as participantes escolheram um nome fictício para ser usado na transcrição, garantido o sigilo para o tratamento e a socialização dos resultados.

1 Disponível em: https://www.youtube.com/watch?v=64kqOYkfCsk. Acesso em: 05 abr. 2018. 
A leitura flutuante foi utilizada para o tratamento dos dados e permitiu identificar palavras e temas que se repetiam, a fim de que pudéssemos elaborar os eixos analíticos. Foram, assim, elaborados dois eixos: 1) O sujeito como construção cultural e as consequências sociais de se autorrepresentar como mulher; 2) As influências da mídia na produção do corpo da mulher: padrões, sentimentos e atuação profissional em Educação Física.

\section{CORPO, MULHER E MÍDIA}

Conforme Goldenberg (2002), o discurso dos meios de comunicação é potente para registrar as marcas do imaginário da sociedade, no processo de constituição da identidade cultural. Pode-se inferir que a mídia institui padrões estéticos que valorizam o corpo tido como perfeito, divulgando-o como referência e padrão a ser seguido.

De acordo com Queiroz (2000, p. 19), o "[...] corpo é de fato apropriado, adestrado pela cultura, concebido socialmente, alterado segundo crenças e ideais coletivamente estabelecidos." Essa espécie de controle social pode ser percebida na forma como o corpo é exibido em diferentes veículos de comunicação: fotografias, filmes, propagandas publicitárias etc., os quais, dentre outras estéticas corporais, acabam por produzir uma representação dito ideal para o corpo da mulher.

Para Daolio (1995), trata-se de compreender o corpo como fonte primária de ação e comunicação moral, no interior da sociedade. Não podemos pensar em um indivíduo que não seja fruto da cultura. Nesse sentido, não podemos imaginar o corpo como algo "natural". O indivíduo reconhece a si mesmo como um ser que se constrói fazendo relações, tomando decisões, se apropriando de costumes e normas que o autor chama de "processo de inCORPOração" (DAOLIO, 1995, p. 25).

Seria então reducionista pensar o corpo somente como uma estrutura biológica. O corpo é cercado por significados criados pela sociedade, em diferentes culturas. Kofes (1994) afirma que o corpo é expressão da cultura; assim, cada cultura se expressa através de diferentes corpos.

Atualmente, a representação do corpo, principalmente do corpo da mulher, é utilizada pela mídia, em particular pela publicidade, como um importante estímulo ao consumo. Goldenberg (2002) associa o corpo a um "objeto de consumo", pois, antes, a publicidade exaltava as vantagens de um produto e, atualmente, produz o consumo como estilo de vida, fabricando um produto próprio: o consumidor. Nessa perspectiva, para além de sua dimensão biológica, o corpo se transformou em objeto de desejo que pode ser adquirido a partir do investimento em tecnologias e produtos que visam a se adequar à representação almejada com determinado tipo de estética.

Segundo Lasch (apud GOLDENBERG, 2002, p. 32), os sujeitos, na condição de consumidores, demonstram-se intranquilos e insatisfeitos com sua aparência. Assim, abrem-se espaços para que a promessa de um corpo considerado perfeito seja explorada, mercadologicamente, e se constitua como um potente mecanismo de subjetivação.

O corpo humano é explorado por diversos discursos midiáticos e, em muitos casos, é exposto como um composto de partes suscetíveis de melhoramento. O corpo tornou-se o mais belo espetáculo da sociedade contemporânea, a qual obriga o indivíduo, em particular 
a mulher, a submetê-lo a modernas intervenções cirúrgicas, a dietas e a exercícios físicos, com o objetivo de atingir determinado padrão (BARBOSA, 2011).

Barbosa (2011) esclarece que esse processo é realizado com a finalidade de obter um corpo propício a aumentar desejos e prazeres sensuais, permitindo que os sujeitos se adequem a determinados padrões sociais. Dessa maneira, muitos e muitas passam a investir em seus corpos, para que possam ser compreendidos/as como possíveis e desejáveis, no plano cultural das relações humanas.

Para Goldenberg (2002, p. 9), “[...] cada indivíduo é considerado responsável (e culpado) por sua juventude, beleza e saúde: só é feio quem quer e só envelhece quem não se cuida." A autora argumenta que o sujeito "em forma" (ou em fôrma?) se apresenta como um sucesso pessoal, ao qual todos devem aspirar, pois a sociedade que afirma que todos podem e devem ser magros e belos institui representações de inapropriados aos que não seguem tais normas.

A mídia participa ativamente daquilo que Baudrillard (apud GOLDENBERG, 2002, p. 97) chamou de "moralização do corpo feminino", no qual as mulheres são responsabilizadas por seus corpos, tanto por suas formas quanto por seu envelhecimento. Esses aspectos contribuem para a produção de determinado padrão de beleza, o qual, em muitos casos, instaura assimetrias de gênero, desigualdades e discriminações contra as mulheres, principalmente as que produzem uma estética corporal na contramão das normalizações corporais de feminilidade instituídas.

O termo mídia, muitas vezes, é usado como sinônimo da expressão "meios de comunicação" e pode, segundo Eagleton (1991 apud FONSECA 2011), ser entendido como complexo de meios de comunicação que envolve mensagem e recepção, através de diversas formas, cuja característica central é a manipulação de elementos simbólicos. Já conforme Fluger e Ferreira (2018), mídia pode ser definida como uma área técnica de propaganda, relacionada com a veiculação de mensagens comerciais.

Podemos destacar diferentes formas de mídia: mídia de massa, que se refere a veículo ou campanha com o objetivo de atingir o maior número de pessoas possíveis; mídia eletrônica, concernente ao conjunto de meios de comunicação que necessitam de recursos eletrônicos como, por exemplo, televisão, rádio, celular etc.; mídia espontânea, ou seja, publicidade gerada e repercutida em forma de notícia; mídia impressa; mídia digital, internet, meio de comunicação em tempo real etc (FLUGER; FERREIRA, 2018).

No que tange à mídia televisiva, em poucos minutos de um intervalo comercial de algum programa de TV, somos bombardeados com representações sobre mulheres, permeadas por estereotipias que reduzem a feminilidade ao consumo e (re)produzem a ideia da mulher como objeto.

Ao tratar de outra tipologia de mídia, Sant'Anna (1995) reitera a assertiva acima, ao sustentar que as revistas femininas são veículos eficazes na difusão social de técnicas estéticas. Um exemplo seria pensar nas capas de revistas nas quais a publicidade segue certo padrão de perfeição, apresentando um corpo medido, calculado e artificialmente preparado, o que se torna uma poderosa mensagem de corpolatria. ${ }^{2}$

2 Segundo Wanderley Codo e Wilson Senne (2004), a corpolatria é o cuidado excessivo com o próprio corpo, mas no sentido de aperfeiçoamento estético e não da preservação da saúde. Para maiores informações, ver: CODO, W.; SENNE, W. O que é corpo(latria). São Paulo: Brasiliense, 2004. 
Nesse sentido, caberia indagar: quais os efeitos dessas representações para a construção do corpo feminino? Como mulheres de diferentes classes sociais, origens étnicas, orientações sexuais e idade recebem essas informações? Quais os impactos desses discursos na manutenção da violência de gênero e contra a mulher, nos espaços sociais?

Cientificamente, alguns estudos nos auxiliam a compreender os processos de produção social dos corpos considerados "adequados" para as mulheres (LOURO, 1997; GOLDENBERG, 2002; SAMARÃO, 2007). Os estudos de gênero, por exemplo, permitem problematizar o corpo da mulher (e dos homens!) como uma constante, e repetitiva, produção pautada na ideia ou ideal de feminilidade.

É preciso pontuar que o conceito de gênero se contrapõe à ideia de sexo. Se este último se refere às diferenças biológicas entre homens e mulheres (LOURO, 1997), o primeiro diz respeito à construção social e histórica do que é considerado masculino ou feminino (SCOTT, 1995). Nesse sentido, agir e sentir-se como mulher ou homem depende dos significados construídos sobre si, em cada contexto sociocultural.

Segundo Louro (1997), tanto na dinâmica do gênero quanto na dinâmica da sexualidade, as identidades são sempre construídas. Elas não são dadas ou acabadas num determinado momento.

Para Scott (1995), o conceito de gênero perpassa duas questões. Primeiro, deve ser compreendido como construção cultural, um conjunto das representações sociais e culturais elaboradas a partir da diferença biológica percebida entre os sexos. Em um segundo momento, gênero pode ser tomado como uma forma primária de nomear as relações de poder.

Judith Butler (2003) salienta que a própria noção de diferença entre sexos deve ser colocada em suspeição. Segundo a autora, não há a possibilidade de compreender o sujeito fora de um contexto cultural, pois este o precede. Assim, a própria noção de sexo ou de corpo sexuado também pode ser problematizada como uma fabricação da cultura.

Para perspectivas teórico-metodológicas contemporâneas (BUTLER, 2003, 2008), gênero passou a ser uma categoria analítica, representacional, relacional e política, que produz a ideia de corpo dito natural. Operar com a categoria gênero significa desnaturalizar os modos de compreensão sobre os corpos, as identidades e os desejos, possibilitando (re) pensar as práticas sociais humanas como construções, prioritariamente, políticas que se desenvolvem num campo discursivo e histórico de relações de poder (LOURO, 1995).

Dessa maneira, os sujeitos vão se construindo e se reconstruindo, no decorrer de seus processos e relações sociais, fazendo-nos perceber que a leitura das relações de gênero e das relações de poder deve "[...] explorar as complexidades tanto das construções de masculinidade quanto as de feminilidade, percebendo como essas construções são utilizadas como operadores metafóricos para o poder e a diferenciação em diversos aspectos do social" (PISCITELLI, 1998, p. 150).

Conforme Goldenberg (2002), discutir sobre corpo e gênero em outros tempos seria falar de temas fúteis. No entanto, considerando os inúmeros debates, atualmente, tais discussões permitem problematizar as culturas, corporeidades e influências publicitárias como fontes para a constituição de uma subjetividade coletiva. Nesse sentido, é relevante problematizar as relações entre mídia e produção cultural do corpo, questionando como essa padronização é recebida e interpretada por mulheres de diferentes níveis de escolaridade, classe social, pertencimento étnico etc. 
Quando relacionamos o conceito de gênero com as questões nodais da presente proposta investigativa, os discursos publicitários que representam homens e mulheres veiculados pelas diferentes tipologias de mídia parecem partir de padrões de categorização, classificação, hierarquização e ordenação da realidade e das relações entre as pessoas. Nem todos os corpos parecem ideais para estampar capas de revista ou campanhas publicitárias. Segundo Sabat (2005, p. 6), “[...] a propaganda, junto com o seu universo de imagens, é também um meio de 'regulação social' que reproduz padrões mais comumente aceitos pela sociedade." Corpos cis, brancos, ocidentais, que performatizam feminilidades e masculinidades normalizadas e que, aparentemente, se distanciariam das classes populares parecem os mais requisitados pelos veículos midiáticos.

Essas normas regulatórias que incidem sobre os corpos reiteram discursos que legitimam representações de corpo consideradas perfeitas, resultando em diferentes formas de violência contra os sujeitos: institucional, física, psicológica, moral etc. Ser pressionado e pressionar-se para tentar atingir determinado modelo de corpo parece não se estabelecer sem a geração de angústias, estresses e sensações de inadequação e não pertencimento. Muitas mulheres são hostilizadas, quando não seguem determinado modelo de estética, de beleza, ou não se parecem com as mulheres expostas pelos meios de comunicação, sendo cada vez mais pressionadas a se enquadrarem nos padrões de beleza.

Tilio (2014) investigou os padrões e estereótipos midiáticos na formação de ideais estéticos em adolescentes do sexo feminino ${ }^{3}$. O estudo foi composto por 12 estudantes do $9^{\circ}$ ano do Ensino Fundamental, com média de 13 anos de idade. Seu objetivo foi explorar relações entre a exposição midiática e suas influências na construção da autoestima das investigadas, auxiliando a compreender o quanto esses veículos direcionam e redirecionam os padrões estéticos de beleza perseguidos por algumas consumidoras. O pesquisador chegou à conclusão de que existe relação entre os padrões de beleza ofertados pelas mídias e a autoestima e autopercepção das adolescentes colaboradoras da pesquisa. Os padrões estéticos mais referidos pelas participantes como belos foram os de mulheres (celebridades) com elevada exposição pública nas mídias.

Lucio (2019), ao examinar o significado de beleza para mulheres, apontou que, de 3.200 mulheres que participaram da pesquisa, $40 \%$ não se sentiam à vontade para se definirem como bonitas. Apenas $2 \%$ se definiram assim, enquanto $31 \%$ utilizaram o termo natural e $29 \%$ preferiram o termo mediana, a fim de falarem sobre suas estéticas. Para $68 \%$ das participantes, a mídia divulga um padrão de beleza que as mulheres nunca poderão alcançar, enquanto $47 \%$ entenderam que apenas mulheres cujo físico pode ser tido como atraente são representadas na cultura popular.

Outro estudo, conduzido por uma equipe de cientistas da Universidade de Flinders (Austrália), entrevistou mais de 80 meninas com idades entre 5 e 8 anos, as quais relataram desejar ser mais magras, já que, para as respondentes, essa característica lhes traria maior aceitação social (UCHOA, 2015). A investigação ainda demonstrou que crianças também sofrem com o padrão de beleza imposto pela mídia.

Assim, a representação feminina na mídia é a referência de beleza e atitude não só para adultos, mas também para crianças. A reprodução desse discurso pode acabar por

3 Terminologia utilizada pelo autor. 
naturalizar algumas relações sociais desde as fases iniciais do desenvolvimento humano. Crianças que fogem aos padrões determinados como, por exemplo, quanto a raça/etnia, gênero ou filiação religiosa, podem vir a ser discriminadas pela aparência ou gostos, e impelidas a acreditar que existiria algo de errado com elas.

Silva, Taquette e Coutinho (2014) também corroboram os dados já explicitados. Ao investigarem 96 estudantes de quatro escolas públicas do Rio de Janeiro, identificaram que a influência da mídia gera padrões de beleza difundidos e difíceis de serem alcançados. Os/ as respondentes reconheceram a existência de um padrão de aparência física imposto pela sociedade, o qual, segundo os/as entrevistados/as, é um padrão difícil de ser correspondido (SILVA; TAQUETTE; COUTINHO, 2014).

Já o estudo realizado por Souza et al. (2013), além de pesquisar a representação do corpo da mulher na mídia, também o relacionou com o estímulo à venda e consumo de drogas. Foram analisados conteúdos de reportagens de 77 exemplares de quatro ${ }^{4}$ revistas comerciais. As autoras identificaram 18 reportagens que associavam o corpo da mulher ao consumo de drogas ilícitas, medicamentos emagrecedores, analgésicos, estimulantes e bebidas alcoólicas.

Conclui-se que a mídia produz a ideia de que as mulheres do sexo feminino devem ser belas e atraentes, para tornarem-se visíveis no contexto social. Ser bela significa ser vista, reconhecida no seu meio social, e isto confere às mulheres autoconfiança, poder, status. (SOUZA et al., 2013, p. 68).

Vargas (2014) problematiza igualmente a construção da imagem corporal, envolvendo fatores socioculturais e a imposição de padrões adotados pela mídia que exaltam o culto ao assim chamado corpo perfeito. A investigação teve como objetivo avaliar a influência da mídia na construção da imagem corporal, realizando uma revisão bibliográfica a partir de artigos científicos socializados em periódicos. Como resultado, a autora conclui que a busca pelo corpo perfeito se torna cada vez mais crescente, proveniente da grande influência da mídia na percepção e construção da imagem corporal.

Os estudos apontados permitem compreender que o corpo feminino produzido pela mídia se adequa às relações tipificadas de gênero com respeito a padrões de feminilidade, tendo influência na construção de determinadas representações sobre o corpo da mulher. Seguindo essas evidências, nossa proposta foi questionar como representações sobre o corpo da mulher produzidas pela mídia afetam o olhar de estudantes de Educação Física sobre seus corpos, bem como qual o impacto que atribuem às influências da mídia na produção do corpo da mulher.

\section{RESULTADOS E DISCUSSÃo}

\section{O sujeito como construção cultural e as consequências sociais de se au- torrepresentar como mulher}

Examinando as narrativas geradas, foi possível compreender que, quando perguntadas sobre o que seria ser mulher, a definição diverge entre uma necessidade de assumir papéis sociais considerados femininos e ir contra normas sociais:

4 As revistas analisadas foram: Veja, Isto É, Boa Forma e Cláudia. 
Pesquisadora: Para vocês, o que é ser mulher?

Isadora: Então, ser mulher para mim é me desafiar todos os dias a ir contra o pensamento da sociedade.

Ana: A primeira coisa que vem à minha cabeça é ter características femininas, a primeira coisa.

Ana: $O$ jeito de se vestir como mulher. Mas isto também não é regra. ${ }^{5}$

Baseados dos trechos em destaque, podemos notar que características como ir contra o pensamento da sociedade, ter características femininas e o jeito de se vestir parecem definir para as estudantes o ser mulher, em nossa sociedade. Todavia, quando acionamos os estudos sobre gênero, percebemos que as representações sobre feminilidade, como características, vestimentas ou comportamentos sociais são construções culturais (SCOTT, 1995; LOURO, 1997).

Para Scott (1995), o gênero é uma construção social que se estabelece através de representações culturais que nos ajudam a compreender as relações de poder. Nesse sentido, os sujeitos passam, desde pequenos, a se adequar a representações construídas pelo social, empenhando-se apenas em reproduzir o que as normas sugerem. Poderíamos indagar, por conseguinte, o que seriam características femininas? Corpos marcados pelo discurso biológico como machos não poderiam produzir tais características?

Segundo Wittig (2006), a categoria mulher é uma produção que se encontra fora do sujeito que fala sobre si. Tal produção carrega traços políticos do processo histórico de subjugação do feminino, sendo que tudo o que se refere à mulher é uma forma de classificação para posicioná-la à margem da ocupação social do macho.

$\mathrm{Na}$ opinião de parte de nossas colaboradoras, o jeito de se vestir também passa a ser assumido com certa naturalidade, sem que se acionem, no plano cognitivo, questionamentos sobre como nossas roupas explicitam normas sociais, podendo ser tidas como estratégias de produção de corpos generificados. Usar saia, em nosso contexto, parece evidenciar certa verdade sobre o feminino, todavia, a história por trás da utilização do kilt ${ }^{6}$ escocês remete a pensar no "[...] orgulho masculino em usar uma peça referência histórica", sendo comum, para tal cultura, a afirmativa "[...] homens de verdade usam kilt." (MACIEL, 2009, p. 12).

Percebe-se que não há unanimidade em relação a essa percepção. Umas das colaboradoras atesta que, em sua visão, "[...] é me desafiar todos os dias a ir contra o pensamento da sociedade.” (Isadora). Tal posição implica pensar nas múltiplas formas de produção do feminino no cotidiano das relações sociais. Louro (1997) argumenta que o conceito de gênero, ao ser tomado como categoria relacional, permite não somente questionar o processo de produção das masculinidades, como também compreender que os projetos e performatizações de gênero entre os sujeitos instauram diferenciadas formas de feminilidade.

Goellner (1999, p. 40) assevera que “[...] as mulheres são diversas entre si”, ou seja, são diferentes em vários aspectos, como vontades, interesses, desejos, sentimentos, crenças religiosas, raça/etnia e grupos sociais a que pertencem, sendo assim plurais.

5 Cabe reafirmar que os nomes das participantes são fictícios e foram escolhidos por elas. A transcrição respeitou a narrativa conforme foi fornecida pelas colaboradoras, de modo que desvios de linguagem foram mantidos.

6 Peça de vestuário, tradicional na história da Escócia, no formato de saia e com pregas na parte posterior. 
Tais produções, como relatado pela colaboradora, questionam determinados padrões que tendem a organizar a mulher em torno de uma feminilidade padrão. Para Halberstam (1998), a produção de outras formas do feminino é historicamente visível e anunciaria certa fuga do normativo, o que aqui chamaríamos de microrresitências, ao remetermos à produção cotidiana de estratégia de questionamentos das normas regulatórias do gênero.

É oportuno notar que uma das participantes destaca o fato de que ser mulher não depende de uma verdade biológica sobre o corpo. Antes, de como você é lida socialmente, a partir de algumas representações:

Fernanda: Para definir mulher, você não pode ir só pelo lado biológico.

Isadora: Até o estilo de roupa que você acabou de usar define se você é uma mulher ou não, se você é afeminada ou masculinizada, e ainda define sua orientação sexual, se você é lésbica ou se você é hétero.

Com base nas percepções anunciadas, questionamos que não é o corpo biológico que define a identidade, mas como o sujeito significa seu corpo, inclusive, podendo modificá-lo. Os corpos assumem formas e condutas, por meio de incorporações e discursos nas relações sociais, as quais são, muitas vezes, naturalizadas (BUTLER, 2003).

Para Butler (2008), a materialização dos discursos de gênero (poderíamos pensar na produção de bens consumíveis como, por exemplo, roupas) tendem, por ser considerada legítima e ser reiterada por diversas instituições, a gerar um efeito de verdade sobre os corpos e identidades. A frase: diga-me o que vestes que te direis quem és, didaticamente, poderia ser uma interpretação da política do performativo (BUTLER, 2003, 2008). Tal assertiva também remete a pensar na necessidade de legitimação dos discursos sobre as diferenças sexuais como definidores da noção de naturalização de nossos corpos. Por não questionarmos, parece que determinados comportamentos, roupas, posições sociais que devemos assumir são, naturalmente, diferentes para homens e mulheres.

É interessante observar que, mesmo ao tentarem definir a mulher com base em trejeitos e roupas, as estudantes são sensíveis à compreensão de que recusar determinados papéis concebidos como apropriados para a mulher não as faz menos feminina. Tal fato demonstra certa ruptura com padrões ou estereótipos:

Rita: Isto é esterétipo. Porque acho que a pessoa não deixa de ser menos feminina pela escolha de sua vestimenta. Só porque ela não gosta de passar maquiagem, ou porque ela não gosta de passar batom, ela não vai ficar menos feminina por isso.

Vemos aqui mais uma microrresistência que leva a questionar os modos pelos quais a identidade mulher é construída pelos discursos. Porém, Butler (2003) alerta que, quando uma mulher não se apresenta socialmente como feminina, ela é vista com olhares de estranhamento. Tal fato permite problematizarmos os mecanismos de reordenação social que incidem sobre os corpos, para readequá-los a determinada categoria normativa prescrita pelo gênero. As diferentes práticas de violência contra a mulher, o feminicídio e a lesbofobia são exemplos dessas estratégias. 


\section{As influências da mídia na produção do corpo da mulher: padrões, sen- timentos e atuação profissional em educação física}

Algumas narrativas fornecidas apontaram que, para as estudantes, a mulher se torna objeto de discursos que tentam generalizar percepções sobre suas estéticas.

Paola: Fica dificil, porque não tem meio termo: se você é demais você é considerada patricinha; se você é de menos, é considerada um homem [...] você tem que ser assim.

O imperativo de gênero tende a construir representações que aprisionam as mulheres em determinadas formas de existir. Ou seja, não é possível, muitas vezes, produzir em seus corpos símbolos e significados que afastem o corpo da mulher do considerado pela sociedade como feminino (LOURO, 1995; PRADO; ALTMANN; RIBEIRO, 2016). Quando uma mulher não se apresenta socialmente, expressando características da feminilidade reconhecidas como o ideal, torna-se alvos de olhares de estranhamento. A fala de Paola também é potente para assumirmos que as relações de gênero, dentro de um mesmo grupo, configuram classificações que visam a hierarquizar os modos aceitos como mais adequados de se representar mulher entre os próprios corpos marcados pelo dispositivo de sexo.

Quando as colaboradoras foram questionadas sobre a relação que a mídia estabelece com seus corpos, uma delas afirma que a mídia possui influência na padronização do corpo, mas que cuidar do corpo pode ser um hábito ou prática prazerosa. Porém, ao final de sua fala, ela comenta: "[...] meu sonho é ter o corpo delas", o que parece indicar, de certa maneira, o impacto de determinadas representações midiáticas sobre o corpo da mulher no processo de construção de sua subjetividade:

Entrevistadora: Vocês acham que a mídia possui influência sobre a relação que a mulher estabelece com seu corpo?

Isadora: $O$ tempo todo. Mas eu também acho que depende, a midia tem sim influência, mas às vezes a pessoa está na musculação porque ela gosta e não para se adequar. Eu não tenho o corpo da mídia, mas eu gosto de praticar musculação, não só porque meu sonho é ter o corpo delas [risos], é lógico que eu quero!

Isadora ainda complementa: "Eu queria sim ter o corpo da Cláudia Leitte, ${ }^{7}$ não sou hipócrita de falar que não, o corpo dela é maravilhoso". Assim, poderíamos afirmar que, mesmo uma colaboradora, a qual, em determinados momentos da condução do grupo, questionou o que é ser mulher, parece ser cooptada pelo ideal de um tipo de corpo que entende como belo. Para a colaboradora, talvez um dos impactos das representações midiáticas sobre seu corpo seja o desejo de produzi-lo a partir do que considera como uma espécie de símbolo de boa forma, a cantora em questão.

Sobre isso, Zozzoli (apud FLOR, 2009, p. 268) avaliou a maneira como as revistas voltadas para o público feminino exploram certo padrão de boa forma, em seus conteúdos. A análise mostrou que as capas de revistas induzem as mulheres a determinados padrões de

\footnotetext{
Cantora, compositora, apresentadora e empresária brasileira.
} 
beleza e boa forma. Mais de três quartos das capas dos veículos de comunicação dirigidos às mulheres, analisados pelo estudo, apresentavam um título que se referia ao melhor modo de mudar a aparência física.

Conforme as colaboradoras, a mídia possui certa influência no que se refere a ditar modelos de corpos tidos como perfeitos. As entrevistadas apresentam consciência dessa imposição, porém, é difícil se desvencilhar das marcas que a mídia causa:

Entrevistadora: E para você, Paula? Você acha que a mídia estabelece essa relação?

Paula: Eu acho que sim. Igual a Isadora estava falando, não necessariamente. Tem gente que gosta [de seguir os modelos midiáticos].

Rita: Mas isso é recente. Porque, antes, as pessoas iam [na academia] para ter o corpo da mídia.

Paola: É, buscam ter o corpo "top".

Rita: $\dot{E}$.

Verificamos, nas falas, que as graduandas são sensíveis a perceber, de certo modo, que as representações produzidas pelos diferentes discursos midiáticos sobre o corpo da mulher impactam, de alguma maneira, a busca por determinado padrão estético. Como demonstrado por Rita, tal fato incide na própria procura das mulheres por academias de ginástica.

Quanto à busca por um padrão corporal, Freitas et al. (2010) ressaltaram que a estética é apontada como justificativa para as mulheres se exercitarem. Ao buscarem a atividade física como intervenção estética, elas almejam mudanças em seus corpos. Muito dessa busca remete às representações sobre mulheres acionadas pelos discursos midiáticos.

De acordo com Novais (2001), o desejo de melhorar a aparência física é um fenômeno sociocultural, sendo mais importante que sua satisfação econômica, profissional e/ou afetiva. Segundo o autor, seria a preocupação com a aparência o que direcionaria cada vez mais as pessoas a praticarem atividades físicas.

Uma das consequências em não se adequar aos padrões corporais esperados são os sentimentos negativos provocados pela falta de senso de pertencimento a determinados grupos. Essa produção de sensações para com o próprio corpo pode ser tomada como uma forma de violência.

Fonseca, Ribeiro e Leal (2012), em uma análise sobre a violência doméstica contra a mulher, descrevem a produção de sentimentos negativos, tais como tristeza, medo, preocupação e sentimento de impotência, como uma das faces da violência sofrida por elas. Em nossa investigação, percebemos que a produção de padrões corporais modelados pela mídia também causa sentimentos negativos para com sua autoimagem. Tal fato poderia nos fazer problematizar as representações consideradas como adequadas para os corpos, veiculadas pelas diferentes mídias, como uma espécie de violência contra os sujeitos que, como consequência, geram sentimentos de negatividade para consigo:

Rita: Mas, às vezes, a pressão da mídia é tanto que a pessoa acaba não tendo direito, ela não tem escolha: ou ela entra no padrão, ou ela... sei lá... é meio que excluída, sabe?

Isadora: Vou ser bem sincera pra você: a mídia faz a gente se sentir mal, eu acho que a mídia é ruim para eles mesmos, porque devem ser sempre perfeitos. 
A partir das falas das estudantes, podemos igualmente identificar indícios sobre a representação que possuem acerca da relação entre corpo e prática profissional em Educação Física. Observamos certa preocupação acerca da produção de determinados modelos de comportamento, condutas e materialização do corpo, quando relacionados a uma futura inserção no mercado de trabalho como profissional da área.

Segundo elas, para conseguirem espaço na área de Educação Física, devem se adequar ao modelo de corpo esperado para uma profissional. Tal corpo corresponderia a uma representação estética de baixa taxa de gordura corporal, músculos definidos e torneados e estética que transmita uma representação para as/os clientes de corpo saudável. Como disse Ana, para uma futura atuação, "tem que ter o perfil".

Ana: Eu não gosto do meu corpo. Eu tento melhorar, só que, ao mesmo tempo, um pouco é biótipo, o jeito de ser, genética.

A prevalência da dimensão estética do corpo, na qual estilo, forma e aparência parecem contar como seus maiores atributos, indica que, para as colaboradoras, seus corpos impactam de maneira significativa na possibilidade ou não de conseguir um emprego e de serem respeitadas em sua futura profissão.

Isadora: A mídia impõe que você tem que ter o corpo perfeito, para você ser profissional.

Fernanda: Por que, se a professora não consegue atingir o objetivo, como é que ela vai fazer o aluno atingir? Esse é o pensamento da sociedade.

Paola: Tem academia que não aceita você ser baixa, gorda, e várias outras exigências.

Ana: Tem que ter o perfil.

Fernanda: [...] por exemplo: para eu trabalhar lá fora, em uma academia, eu vou ter que ter um corpo perfeito. Isso não quer dizer que eu vou saber dar um treinamento. Por exemplo: eu não tenho o corpo bonito, se eu chegar em uma academia, aquela professora que tem o corpo bonito não quer dizer que ela vai saber dar um treinamento melhor que o meu.

Paula: Exatamente.

A partir da fala de Isadora, percebemos que a competência profissional parece ser resumida a um estereótipo de corpo idealizado pela sociedade, colocando o atributo da aparência física na frente do conhecimento. Refletindo em função dos trechos acima, indagamos: quem disse que a representação considerada ideal remete ao conhecimento?

Palazzi e Cardoso (2017) realizaram uma pesquisa para investigar os fatores que mais impactam na intenção de compra do serviço de personal trainer ${ }^{8}$ Nos resultados da pesquisa, foi possível perceber que a aparência física do profissional tem grande significância na hora de adquirir seus serviços. A aparência se configura, inclusive, como uma estratégia do profissional para que possa demonstrar seu conhecimento, tornando sua aparência um fator que parece reforçar as competências profissionais adquiridas por meio da formação profissional. No estudo, é indicado que uma boa imagem permite uma melhor aceitação pelos clientes.

8 Treinador pessoal (do inglês personal trainer). 
Silva, Saenger e Pereira (2011) procuraram igualmente investigar os fatores associados à imagem corporal em estudantes de Educação Física. 230 estudantes responderam ao questionário com questões relacionadas à imagem corporal e a práticas de atividade física. $67 \%$ das estudantes confirmam a prevalência de insatisfação com a imagem corporal. Esse resultado está de acordo com outros estudos com universitárias.

Percebemos que, apesar de essas mulheres estabelecerem críticas aos modos sociais de produção de corpos, também são capturadas por essas representações. Isso demonstra um complexo jogo de poder entre capturas e fugas dos modelos esperado para elas. Caberia indagar até que ponto essas relações fazem com que busquem sempre melhorar seus corpos, a fim de se adequarem e/ou se sentirem bem, quando recebem as representações imagéticas sobre o corpo da mulher produzidas pelos diferentes veículos midiáticos.

\section{CONSIDERAÇões FINAIS}

O artigo procurou compreender como representações midiáticas afetam o olhar de estudantes de Educação Física sobre seus corpos, bem como qual o impacto que atribuem às influências da mídia na produção do corpo da mulher. A partir das análises empreendidas, observamos que tanto as representações sobre o que é ser mulher quanto as consequências dessa representação na esfera da construção das relações sociais perpassam as narrativas das colaboradoras. Embora, em alguns momentos do GF, as estudantes questionem a dimensão biológica como característica principal da definição da mulher, elas se autorrepresentam com base em linhas de captura produzidas por modelos generificados. Para elas, possuir características femininas, o jeito de se vestir e a feminilidade foram falas recorrentes na discussão do GF e que, em suas visões, definem suas representações sobre ser mulher.

Também argumentamos que as colaboradoras percebem algumas consequências sociais que impactam na vida das mulheres, inclusive nas suas. Segundo elas, relações de poder subjugam a representação da mulher ao domínio masculino e são sensíveis à compreensão de que quem foge do modelo considerado padrão é hostilizada no plano social.

Três formas de influência foram identificadas com respeito às representações midiáticas sobre seus corpos: 1) a produção de padrões corporais, os quais, inclusive, são utilizados pelas estudantes para se referirem a outros corpos; 2) os sentimentos negativos gerados para com suas próprias imagens corporais; e 3) as possíveis consequências profissionais que podem ser geradas pela não adoção de um modelo de corpo pré-determinado, no que concerne à atuação em Educação Física.

Tais representações impactam na produção de sentimentos negativos nas estudantes, fazendo com que se sintam mal em relação a si, quando se comparam com outros corpos. Sugerimos que tais sentimentos são produzidos pelas normas regulatórias dos corpos e dos padrões de gênero, que, em muito, capturam as estudantes, ao ponto de fazer com que elas produzam sentimentos negativos sobre seus corpos.

A representação que possuem acerca da relação entre corpo e prática profissional, na área da Educação Física, emergiu como consequência para a atuação como futuras profissionais. Demonstraram certa apreensão quanto à produção de determinados modelos, pois a ideia de perfil para atuar na área parece estabelecer relações com determinado padrão de 
corpo. Para as colaboradoras, tal relação também aparece permeada por representações midiáticas sobre os corpos das mulheres.

\section{REFERÊNCIAS}

ANDRÉ, M. E. D. A.; LÜDKE, M. Pesquisa em Educação: abordagens qualitativas. 2. ed. São Paulo: E.P.U., 2013.

BARBOSA, M. R.; MATOS, P. M.; COSTA, M, E. Um olhar sobre o corpo: o corpo ontem e

hoje. Psicologia \& Sociedade. Porto Alegre, v. 23, n. 1, p. 24-34, 2011.

BUTLER, J. Problemas de gênero: feminismo e subversão da identidade. Rio de Janeiro: Civilização Brasileira, 2003.

BUTLER, J. Cuerpos que importan: sobre los limites materiales y discursivos del "sexo". 2. ed. Buenos Aires: Paidós, 2008.

CODO, W.; SENNE, W. O que é corpo(latria)? São Paulo: Brasiliense, 2004.

DAOLIO, J. Os significados do corpo na cultura e as implicações para a Educação Física. Movimento. Florianópolis, ano 2, n. 2, p. 24-28, jun. 1995.

FLOR, G. Corpo, mídia e status social: reflexões sobre os padrões de beleza. Estud. Comum. Curitiba, v. 10, n. 23, p. 267-274, set./dez. 2009.

FONSECA, D.; RIBEIRO, C.; LEAL, N. Violência doméstica contra a mulher: realidades e representações sociais. Psicologia \& Sociedade. Belo Horizonte, v. 24, n. 2, p. 307-314, 2012.

FONSECA, F. Mídia, poder e democracia: teoria e práxis dos meios de comunicação. Revista brasileira de ciência política. Brasília, n. 6, jul./dez. 2011.

FREITAS, C.; LIMA, R.; COSTA, A.; FILHO, A. O padrão de beleza corporal sobre o corpo feminino mediante o IMC. Rev. bras. Educ. Fís. Esporte. São Paulo, v. 24, n. 3, p. 389-404, jul./set. 2010.

FURGLER, N.; FERREIRA, I. Dicionário de Mídia. 3. ed. Rio de Janeiro: Direção Geral de Negócios, 2018. Disponível em: < https://negocios8.redeglobo.com.br/PDF/MidaKit/ Dicionario\%20de\%20Midia\%202018.pdf $>$. Acesso em: 13 set. 2019.

GOELLNER, S. Imperativos de ser mulher. Motriz. Rio Claro, v. 5, n.1, p. 40-42, jun. 1999. 
GOLDENBERG, M. (Org.). Nu e vestido: dez antropólogos revelam a cultura do corpo carioca. 2. ed. Rio de Janeiro: Record, 2002.

HALBERSTAM, J. J. Masculinidad femenina. Madrid: Egales, 1998.

KOFES, S. E sobre o corpo, não é o próprio corpo que fala? Ou o discurso desse corpo sobre qual se fala. In: BRUHNS, H. T. (Org.). Conversando sobre o corpo. 5. ed. Campinas: Papirus, 1994. p. 45-60.

LOURO, G. L. Gênero, História e Educação: construção e desconstrução. Porto Alegre, Educação \& Realidade. Porto Alegre, v. 20, n. 2, p. 101-132, jul./dez. 1995.

LOURO, G. L. Gênero, Sexualidade e Educação: uma perspectiva pós- estruturalista. 6. ed. Petrópolis: Vozes, 1997.

LUCIO, C. F. A verdade sobre a beleza. Central de cases ESPM. Disponível em: < file://C:/Users/User/Downloads/dove\%20sim.pdf>. Acesso em: 13 set. 2019.

MACIEL, D. Alfaiataria e feminilidade: representações de gênero na revista Elle Brasil. 2009. 69 f. Monografia (Especialização em Educação, Sexualidade e Relações de Gênero) - Faculdade de Educação, Universidade Federal do Rio Grande do Sul, Porto Alegre, 2009.

MINAYO, M. C. O desafio do conhecimento: pesquisa qualitativa em saúde. 9. ed. São Paulo: Hucitec, 2006.

MORGAN, D. Focus Groups as Qualitative Research. London: Sage, 1997.

NOVAES, J. Estética: o corpo na academia. Rio de Janeiro: Shape, 2001.

PALAZZI, J.; CARDOSO, M. Fatores que impactam a intenção de compra do serviço de personal trainer. Podium Sport, Leisure and Tourism Review. São Paulo, v. 6, n. 4, p. 330-332, set./dez. 2017.

PISCITELLI, A. Gênero em Perspectiva. Cadernos Pagu. Campinas, n. 11, p. 141-155, 1998.

PRADO, V. M.; ALTMANN, H.; RIBEIRO, A. I. M. Condutas normalizadas na educação física: uma questão de gênero? Currículo sem Fronteiras. Porto Alegre, v. 16, n. 1, p. 5977, jan./abr. 2016.

QUEIROZ, R. O. Corpo do brasileiro. São Paulo: Senac, 2000.

SABAT, R. Imagens de gênero e produção de cultura: gênero em discursos da mídia. In: FUNCK, S. B.; WIDHOLZER, N. (Org.). Gênero em discursos na mídia. Florianópolis: Mulheres; Santa Cruz do Sul: Edunisc, 2005. p .93-118. 
SAMARÃO, L. O espetáculo da publicidade: a representação do corpo feminino na mídia. Contemporânea. Rio de Janeiro, n. 8, p. 45-57, 2007.

SANT'ANNA, D. B. Cuidados de si e embelezamento feminino: fragmentos para uma história do corpo no Brasil. São Paulo: Estação Liberdade, 1995.

SCOTT, J. Gênero: Uma categoria útil de análise histórica. Educação \& Realidade. Porto Alegre, v. 20, n. 2, p. 71-99, jul./dez. 1995.

SILVA, M.; TAQUETTE, S.; COUTINHO, E. Sentidos da imagem corporal de adolescentes do ensino fundamental. Rev. saúde pública. Rio de Janeiro, v. 48, n. 3, p. 438-444, 2014.

SILVA, T.; SAENGER, G.; PEREIRA, E. Fatores associados à imagem corporal em estudantes de Educação Física. Motriz. Rio Claro, v. 17 n. 4, p. 630-639, out./dez. 2011.

SOUZA, M.; OLIVEIRA, R.; NASCIMENTO, E.; CARVALHO, E. Droga de corpo! Imagens e representações do corpo feminino em revistas brasileiras. Revista Gaúcha de Enfermagem. Porto Alegre, v. 34, n. 2, p. 62-69, 2013.

TILIO, R. Padrões e estereótipos midiáticos na formação de ideais estéticos em adolescentes do sexo feminino. Ártemis, v. XVIII, n. 1, p. 147-159, jul./dez. 2014.

UCHOA, P. Meninas de 6 anos de idade estão insatisfeitas com o corpo. Época online e agências internacionais, n. 355, mar. 2015. Disponível em: <http://revistaepoca.globo.com/ Revista/Epoca/0,EDG69189-6014,00-meninas+de+anos+de+idade+estao+insatisfeitas+com + o+corpo + mostra + pesquisa.html>. Acesso em: 30 nov. 2017.

VARGAS, E. A influência da mídia na construção da imagem corporal. Rev. Bras. Nutr. Clin. Porto Alegre, v. 29, n. 1, p. 73-75, jan. 2014.

WITTIG, M. El pensamiento heterosexual y outros ensayos. 2. ed. Madrid: Egales, 2006.

\section{DADOS DOS AUTORES}

\section{Dieli Martins Queiroz}

Graduada em Educação Física pela Universidade Federal de Uberlândia. dieliqueiroz@, hotmail.com

\section{Vagner Matias do Prado}

Doutor em Educação pela Universidade Estadual Paulista - Presidente Prudente/SP (FCT/ UNESP). Docente da Faculdade de Educação Física e Fisioterapia e do Programa de Pós-Graduação em Educação da Universidade Federal de Uberlândia (UFU).vmp_ef@yahoo. com.br

Submetido em: 25-09-2019

Aceito em: 01-02-2021 